\title{
Avaliação do uso da levedura de descarte da indústria cervejeira na obtenção da aguardente de liquor de laranja
}

\author{
Evaluation of the use of discarded industrial brewer's yeast to obtain \\ orange liquor spirit
}

\author{
Crislaine Alvarenga Perez de Paula', João Bosco Faria ${ }^{1 *}$ \\ "Universidade Estadual "Júlio de Mesquita Filho" (UNESP), Departamento de Alimentos e Nutrição, Araraquara/SP, Brasil \\ *Corresponding Author: \\ João Bosco Faria, Universidade Estadual "Júlio de Mesquita Filho" (UNESP), Departamento de Alimentos e Nutrição, Rodovia Araraquara-Jaú, \\ km 1. CEP: 14801-902. Araraquara/SP - Brasil, e-mail: fariajb@fcfar.unesp.br
}

Cite as: Evaluation of the use of discarded industrial brewer's yeast to obtain orange liquor spirit. Braz. J. Food Technol., v. 20, e2016003, 2017.

Received: Jan. 05, 2016; Accepted: May 02, 2017

\section{Resumo}

O liquor de laranja, subproduto da indústria cítrica brasileira, é atualmente destinado à produção de ração animal, assim como o fermento da indústria cervejeira, que é descartado, após cinco ciclos de produção, contendo ainda alta porcentagem de células viáveis. O objetivo do presente estudo foi avaliar a reutilização da levedura de descarte da indústria cervejeira na produção da aguardente de liquor de laranja, sem reposição do pé-de-cuba, além de avaliar o impacto desta prática na qualidade química e sensorial do produto final. Para isso, foram conduzidas nove bateladas de fermentações, sem reposição do fermento, sendo o liquor assim fermentado, bidestilado em alambiques de cobre, dando origem a três amostras da bebida, que foram postas a envelhecer em ancorotes de castanheira por seis meses. As amostras foram submetidas à determinação dos teores de etanol, cobre, acidez volátil, aldeídos, ésteres, metanol, álcoois superiores, furfural, bem como ao teste de aceitação e intenção de compra. A reutilização do fermento durante a produção da bebida apresentou, ao final das nove bateladas, uma redução de $15 \%$ das células viáveis. Todas as determinações químicas apresentaram-se de acordo com a legislação vigente, exceto o teor de álcool metílico e álcool n-butílico na amostra C. Os testes de aceitação não revelaram diferença significativa nos atributos cor e aroma entre as três aguardentes, mas, nos atributos sabor e impressão global, observou-se diferença significativa na aguardente B. Com base nos resultados obtidos, a reutilização do fermento de descarte da indústria cervejeira na produção da aguardente de liquor de laranja por até três bateladas de fermentação apresentou-se, portanto, como uma boa opção na obtenção desta aguardente, garantindo a fermentação de três bateladas, sem alterações indesejáveis na bebida.

Palavras-chave: Destilado; Teste de aceitação; Subproduto; Bidestilação.

\section{Abstract}

Orange liquor, a by-product of the Brazilian citrus industry, is currently destined for the production of animal feed as also the industrial brewer's yeast discarded after five production cycles, but still containing a high percentage of viable cells. The aim of this study was to evaluate the reuse of the yeast discarded by the brewing industry in the production of orange liquor spirit without replacing the yeast, and evaluate the impact of this practice on the chemical and sensory quality of the final product. Thus nine batch fermentations were carried out without replacement of the yeast, and the fermented liquor double distilled in copper stills, yielding three beverage samples that were aged in chestnut barrels for six months. The ethanol, copper, volatile acidity, aldehyde, ester, methanol, higher alcohols and furfural contents were determined, and the samples submitted to a consumer acceptance and purchasing intention test. At the end of the nine batch fermentations, the reuse of the yeast to produce the beverage resulted in a $15 \%$ reduction in viable cells. All the chemical determinations conformed to current legislation, except for the methyl alcohol and n-butyl alcohol contents of sample $\mathrm{C}$. The acceptance test revealed no significant differences between the three beverages for the attributes of colour and aroma, although there was a significant difference for sample B with respect to the attributes of flavour and overall impression. Based on the results obtained, the reuse of discarded industrial brewer's yeast was shown to be a good option to obtain orange liquor spirit, ensuring at least three fermentation batches without undesirable changes in the drink.

Keywords: Spirit; Acceptance test; By-product; Double distillation. 
Avaliação do uso da levedura de descarte da indústria cervejeira na obtenção da aguardente de liquor de laranja

Paula, C. A. P.; Faria, J. B.

\section{Introdução}

A aguardente de liquor de laranja é uma bebida obtida a partir dos resíduos das indústrias cítrica e cervejeira, inicialmente proposta por Roçafa Junior et al. (2005). O liquor é fermentado por leveduras de descarte da indústria cervejeira, sendo bidestilado e posto a envelhecer em ancorotes de carvalho (ROÇAFA JUNIOR et al., 2005).

Atualmente, o Brasil, com características climáticas propícias ao cultivo de laranja, é considerado o maior produtor e exportador de suco de laranja do mundo, gerando um grande volume de resíduos, dentre os quais o liquor de laranja (CITRUSBR, 2016).

Em estudos posteriores relacionados à referida aguardente, foi avaliada a viabilidade da utilização do fermento da indústria cervejeira na fermentação do liquor de laranja. Os resultados obtidos revelaram a obtenção de uma bebida de qualidade e com um perfil sensorial distindo da cachaça (SAITO, 2007).

Nesse sentido, diversos estudos têm sido realizados na área de reaproveitamento de resíduos, valendo citar a produção de bioetanol a partir da casca de limão e de outras frutas cítricas (BOLUDA-AGUILAR; LÓPEZ-GÓMEZ, 2013; WILKINS et al., 2007), a utilização de resíduos amiláceos da agroindustrialização da mandioca (BRINGHENTI; CABELLO, 2005), o uso de soro de queijo (BARBOSA et al., 2010) e da casca e da borra de jabuticaba (ASQUIERI et al., 2009).

Na produção da cachaça, durante o processo de fermentação, é utilizado o processo de decantação, que consiste em separar o caldo fermentado do fermento por decantação, na dorna. Assim, é possível a utilização do mesmo fermento (pé-de-cuba) em vários processos de fermentação, sem a necessidade de troca ou reposição do fermento diversas vezes durante a safra (MUTTON; MUTTON, 2010).

Nesse sentido, foi objetivo do presente estudo avaliar a reutilização da levedura de descarte da indústria cervejeira na produção da aguardente de liquor de laranja, realizando diversos processos fermentativos sem a reposição do pé-de-cuba, visando avaliar o impacto desta prática na qualidade química e sensorial do produto final.

\section{Material e métodos}

\subsection{Obtenção das aguardentes de liquor de laranja}

As três aguardentes estudadas foram obtidas a partir do liquor de laranja, oriundo de uma indústria de suco de laranja, após a primeira prensagem do bagaço. $\mathrm{Na}$ fermentação do liquor, foram utilizadas leveduras (Saccharomyces cerevisae) de descarte da indústria cervejeira, contendo aproximadamente 97\% de células viáveis.

O liquor de laranja, após ser diluído a $15^{\circ}$ Brix, foi posto a fermentar pelas leveduras de descarte da indústria cervejeira à temperatura ambiente, por 48 horas, com monitoramento do pH (IAL, 2005) e do teor de sólidos solúveis totais (AOAC, 1995), sendo verificada, ao final de cada batelada de fermentação, a viabilidade do fermento, conforme Bonneu et al. (1991).

Assim, foram realizadas nove bateladas de fermentações utilizando-se o mesmo pé-de-cuba, sem reposição do fermento, sendo o liquor fermentado, em cada batelada, posteriormente destilado em alambique de cobre, com capacidade de 300 litros, e aquecido por chama direta, dando origem a nove destilados alcoólicos com graduação de 30\% v/v de etanol.

O conjunto de cada três destilações foi então bidestilado em alambique de cobre com capacidade de 20 litros, também aquecido por chama direta, sendo então separadas as frações "cabeça" (volume corresponde a $2 \%$ do volume total da aguardente monodestilada), "coração" (volume coletado até a bebida atingir a graduação de $60 \%$ v/v de etanol) e a "cauda" (fração final do processo de bidestilação). Dessa forma, as frações "coração" correspondentes a cada bidestilação deram origem às três aguardentes (A, B e C), que foram então armazenadas por um período de seis meses em ancorotes de castanheira novos, com capacidade de cinco litros, adquiridos em uma tanoaria da região da cidade de Araraquara. Segundo Piggott et al. (1989), o teor alcoólico elevado das bebidas destiladas (a partir de 60\% v/v) é mais efetivo na extração dos componentes presentes na madeira, pois os compostos responsáveis por aroma e sabor são mais solúveis em álcool do que em água.

O processo de envelhecimento foi realizado em duplicatas, sendo utilizados dois ancorotes para cada aguardente. E, ao final do processo, as três aguardentes tiveram o teor alcoólico ajustado com água destilada para $40 \%$ v/v.

\subsection{Monitoramento do $\mathrm{pH}$, sólidos solúveis totais e viabilidade celular do fermento}

$\mathrm{O} \mathrm{pH}$ do liquor de laranja foi determinado por leitura direta em pHmetro (IAL, 2005) e a determinação do teor de sólidos solúveis totais ( ${ }^{\circ}$ Brix) durante a fermentação deu-se por leitura direta em refratômetro, conforme metodologia definida pela AOAC - Association of Official Analytical Chemists (AOAC, 1995).

Ao final de cada processo de fermentação, foi realizada a contagem de células viáveis em câmara de Neubauer, utilizando o corante azul de metileno, segundo Bonneu et al. (1991).

\subsection{Determinação da composição química das amostras de aguardente de liquor de laranja}

Logo ao final do processo de envelhecimento, sem diluição das amostras (60\% v/v), foram realizadas, nas três amostras suprarreferidas, as determinações dos teores de 
Avaliação do uso da levedura de descarte da indústria cervejeira na obtenção da aguardente de liquor de laranja

Paula, C. A. P.; Faria, J. B.

etanol, cobre e acidez volátil, segundo metodologia descrita na Instrução Normativa n. ${ }^{24}$, de 08 setembro de 2005, do Ministério da Agricultura, Pecuária e Abastecimento (BRASIL, 2005a); aldeídos, ésteres, metanol, álcoois superiores (propanol, 1-butanol, 1-amílico) e furfural foram determinados por cromatografia em fase gasosa, com detector de ionização de chama (BORTOLETTO; ALCARDE, 2013; ALCARDE et al., 2012). As análises cromatográficas foram realizadas em cromatógrafo a gás da marca Shimadzu modelo QP-2010 PLUS, com coluna Stabilwax-DA (Crossbond Carbowax polyethylene glycol, $30 \mathrm{~m} \times 0,18 \mathrm{~mm} \times 0,18 \mu \mathrm{m})$ e detector de ionização de chama (FID). As temperaturas do detector e do injetor foram fixadas em $250{ }^{\circ} \mathrm{C}$ e a injeção foi realizada manualmente, com divisão de fluxo (modo split) de 1:25 e volume de injeção de 1,0 $\mu \mathrm{L}$ da amostra, em triplicatas. O fluxo do gás de arraste na coluna $\left(\mathrm{H}^{2}\right)$ foi de $1,5 \mathrm{~mL} \mathrm{~min}^{-1}$, com fluxo total de $42 \mathrm{~mL} \mathrm{min-1}$ e pressão de $252,3 \mathrm{kPa}$. A programação da rampa de temperatura da coluna foi $40^{\circ} \mathrm{C}$ (isoterma de quatro minutos), aumento até $120^{\circ} \mathrm{C}$ a uma taxa de $20^{\circ} \mathrm{C} \mathrm{min}^{-1}$ (isoterma de um minuto) e aumento a $30^{\circ} \mathrm{C} \mathrm{min}^{-1}$ até $180^{\circ} \mathrm{C}$ (isoterma de quatro minutos).

Todos os reagentes utilizados foram de grau analítico (Sigma-Aldrich) e, para as diluições, foram utilizados etanol de grau cromatográfico (Merck) e água ultrapura (Milli-Q).

\subsection{Análise sensorial}

Para a realização do teste de aceitação das aguardentes de liquor de laranja, foram recrutados e selecionados, por meio de questionário, somente consumidores potenciais do produto, maiores de 18 anos. Pessoas portadoras de hepatopatias, alérgicas a bebidas alcoólicas, grávidas ou fazendo o uso de algum tipo de medicamento não foram aceitas na análise sensorial.

Os testes de aceitação foram realizados em cabines individuais, no laboratório de análise sensorial, sob luz branca, por 60 provadores (GUAGLIANONI, 2009). As aguardentes foram avaliadas monadicamente, utilizando-se escala hedônica de nove pontos, conforme descrito por Villanueva et al. (2005). A intenção de compra dos consumidores em relação a cada aguardente também foi avaliada, através de uma escala de 5 pontos ( 1 = certamente não compraria até $5=$ certamente compraria) (MEILGAARD et al., 2006).

O presente estudo foi aprovado pelo Comitê de Ética em Pesquisa da Faculdade de Ciências Farmacêuticas (UNESP), com o número do Certificado de Apreciação e Apresentação Ética (CAAE) 00736912.5.0000.5426.17.

\subsection{Análise de dados}

Os dados dos testes de aceitação foram avaliados quanto a normalidade e homocedasticidade, e submetidos à Análise de Variância (ANOVA) e ao teste de Tukey.
A intenção de compra foi analisada por meio de teste qui-quadrado de Pearson.

O nível de significância adotado no estudo foi de 5\%.

\section{Resultados e discussão}

\subsection{Processo fermentativo do liquor de laranja}

Utilizando-se o sistema de pé-de-cuba, o processo fermentativo do liquor de laranja foi realizado em nove bateladas de fermentação consecutivas, sendo as seis primeiras com duração de 48 horas e as três últimas com 72 horas de duração, todas determinadas com base na redução do teor de sólidos solúveis ( ${ }^{\circ}$ Brix) e na interrupção da produção de gás carbônico.

Na Figura 1, está apresentada a viabilidade celular do fermento de descarte da indústria cervejeira durante as nove bateladas de fermentação consecutivas do liquor de laranja. A viabilidade inicial do fermento, que era de $97,65 \%$, decaiu durante as seis primeiras bateladas apenas cerca de $2 \%$, apresentando ainda, ao final da sexta batelada, uma viabilidade de 95,14\%.

Assim, com base nos resultados obtidos nas seis primeiras fermentações, utilizando-se o mesmo pé-de-cuba, foi observado que, a partir da sétima fermentação, houve uma ligeira queda na viabilidade celular e, na nona fermentação, ao final do processo fermentativo, uma viabilidade celular de aproximadamente 83,00\%. As últimas bateladas (7, 8 e 9), mesmo com o fermento ainda viável, não se revelaram aconselháveis, já que a extensão do tempo de fermentação implica grande risco de contaminação do liquor de laranja por outros microrganismos (bactérias e leveduras selvagens), o que, além da diminuição do rendimento, ainda poderia resultar na produção de compostos capazes de interferir na qualidade da bebida (MUTTON; MUTTON, 2010).

O teor de sólidos solúveis totais diminuiu em média 3,34 ${ }^{\circ}$ Brix durante as três primeiras bateladas

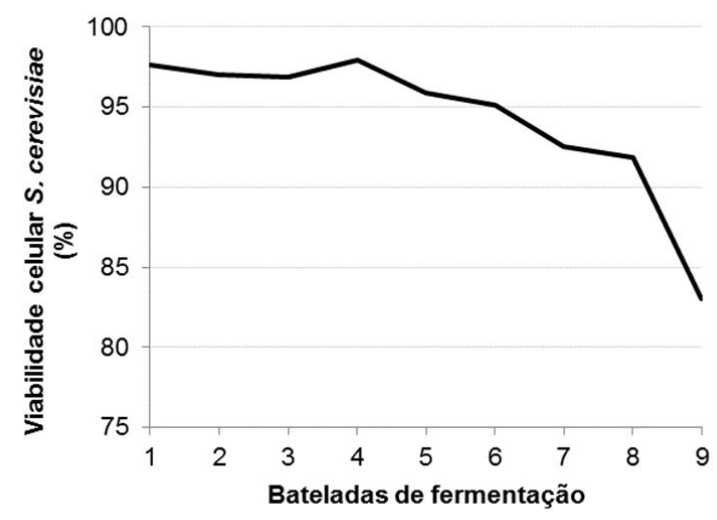

Figura 1. Viabilidade celular do fermento durante as nove bateladas de fermentação. 
Avaliação do uso da levedura de descarte da indústria cervejeira na obtenção da aguardente de liquor de laranja

Paula, C. A. P.; Faria, J. B.

(correspondentes à amostra A) e, durante as nove bateladas de fermentação, a redução dos sólidos solúveis se manteve relativamente constante, não apresentando diferença significativa entre as bateladas; cabe, ainda, destacar que a amostra C (bateladas de fermentação 7, 8 e 9) foi a que apresentou o pior desempenho (redução de aproximadamente $1^{\circ}$ Brix).

Na produção de cachaça, o caldo de cana-de-açúcar puro contém altos teores de sacarose e, quando fermentado de forma adequada, geralmente apresenta um teor de etanol em torno de 5\% a 10\% (MUTTON; MUTTON, 2010). Já na produção da aguardente de liquor de laranja, o rendimento é inferior, tendo em vista sua composição, que é diferente do caldo de cana-de-açúcar. Além disso, a presença do óleo proveniente da casca, mesmo em baixas concentrações, é um fator negativo para a fermentação devido ao seu efeito tóxico para as leveduras. Note-se que sua remoção também constitui um fator negativo, que envolve processos de alto custo, o que poderia inviabilizar a produção da aguardente. Há relatos na literatura de que o liquor de laranja a ser fermentado não deve apresentar níveis de óleo superiores a 0,08\% (LANZA, 2003).

Zinnai et al. (2013), avaliando a diferença da velocidade de fermentação da glicose e da frutose, observaram que a fermentação da frutose é influenciada pela quantidade de etanol presente no meio, se tornando cada vez mais lenta e atingindo um ponto estacionário, no qual a levedura deixa de fermentar, mesmo com frutose ainda disponível no meio. Sabendo-se que o liquor é constituído de aproximadamente $6 \%$ de sacarose, além de outros açúcares redutores, e da presença do óleo da casca da laranja, tais fatores podem contribuir para um rendimento inferior da fermentação (BRADDOCK, 1999).

Roçafa Junior et al. (2005), utilizando o fermento convencional usado na produção de cachaça, para obtenção da aguardente de liquor de laranja, conseguiram uma redução dos sólidos solúveis totais de $5,7^{\circ}$ Brix (de 14 para 8,3 ${ }^{\circ}$ Brix) com bateladas de fermentação de 48 horas. Saito (2007), utilizando o fermento de descarte da indústria de cerveja na produção da mesma bebida, obteve uma redução em média de $9,7^{\circ}$ Brix (de 18,25 para 8,52 ${ }^{\circ}$ Brix) em 24 horas de fermentação e Lorenzeti (2009), também utilizando a levedura cervejeira, em bateladas de 24 horas, conseguiu uma redução média de $5^{\circ}$ Brix (de 16,3 para $11,5^{\circ}$ Brix).

Como as matérias-primas da aguardente de liquor de laranja são subprodutos industriais, é difícil obter-se uma padronização das mesmas. No caso do liquor de laranja, pode haver ainda variações em sua composição, dependendo da época do ano e de variações climáticas, o que certamente poderá influenciar na qualidade final da bebida.

\subsection{Composição química das aguardentes de liquor de laranja}

Os dados referentes à composição química das três aguardentes de liquor de laranja estão apresentados na Tabela 1.

Nas três amostras, a concentração dos componentes químicos analisados atendeu à legislação vigente, exceto no caso dos teores de álcool metílico e álcool n-butílico, para a aguardente C (BRASIL, 2005b).

Os álcoois metílico e n-butílico, considerados contaminantes orgânicos em cachaças e aguardentes, são encontrados ao longo da destilação, porém em maiores concentrações nas primeiras e últimas frações do destilado ("cabeça" e "cauda"). O álcool metílico tem origem da degradação de matéria péctica e é, geralmente, encontrado em maiores teores em destilados de frutas. Quando em concentrações elevadas, esses álcoois têm efeito tóxico e cumulativo no corpo humano, devendo, portanto, ser

Tabela 1. Composição química correspondente à fração "coração" das aguardentes de liquor de laranja (A, B e C).

\begin{tabular}{|c|c|c|c|c|}
\hline Composição química & $\mathbf{A}$ & B & C & Legislação $^{3}$ \\
\hline Acidez volátil em ácido acético ${ }^{1}$ & 51,01 & 96,65 & 144,39 & $0-150$ \\
\hline Aldeídos em aldeído acético ${ }^{1}$ & 14,09 & 9,84 & 10,91 & $0-30$ \\
\hline Ésteres em acetato de etila ${ }^{1}$ & 26,34 & 35,25 & 61,23 & $0-200$ \\
\hline Álcool metílico ${ }^{1}$ & 14,43 & 13,25 & 22,84 & $0-20$ \\
\hline Álcool sec-butanol ${ }^{1}$ & 1,80 & 4,57 & 3,32 & $0-10$ \\
\hline Álcool propílico & 94,06 & 149,48 & 142,62 & - \\
\hline Álcool iso-butílico ${ }^{1}$ & 11,84 & 21,39 & 20,04 & - \\
\hline Álcool n-butílico ${ }^{1}$ & 1,44 & 2,72 & 4,03 & $0-3$ \\
\hline Álcool iso-amílico ${ }^{1}$ & 58,47 & 78,29 & 80,97 & - \\
\hline Álcoois superiores ${ }^{1}$ & 164,37 & 249,16 & 243,63 & $0-360$ \\
\hline Furfural $^{1}$ & 2,17 & 3,51 & 2,89 & $0-5$ \\
\hline Coeficiente de congêneres ${ }^{1}$ & 257,98 & 394,41 & 463,04 & $200-650$ \\
\hline Cobre ${ }^{2}$ & 1,75 & 4,01 & 2,12 & $0-5$ \\
\hline
\end{tabular}

${ }^{1} \mathrm{mg} 100 \mathrm{~mL}^{-1}$ álcool anidro; ${ }^{2} \mathrm{mg} \mathrm{L-1}$; ${ }^{3}$ Brasil (2005b). 
Avaliação do uso da levedura de descarte da indústria cervejeira na obtenção da aguardente de liquor de laranja

Paula, C. A. P.; Faria, J. B.

separados da fração principal ("coração") (MUTTON; MUTTON, 2010; SOUZA et al., 2009; MIRANDA et al., 2006).

A acidez volátil, consideravelmente maior na amostra $C$, apresentando um teor próximo ao máximo permitido pela legislação, se deve provavelmente ao fato de esta amostra ser constituída dos destilados oriundos dos três últimos processos fermentativos ( 7,8 e 9 ), os quais, apresentando maior tempo de duração da fermentação (72 horas), não criaram as condições favoráveis para a realização da fermentação desejada, favorecendo assim a produção de compostos ácidos capazes de comprometer a qualidade do produto final (BRASIL, 2005b; MIRANDA, et al. 2006).

Mesmo dentro dos limites estabelecidos pela legislação, o teor de ésteres também foi maior na amostra $\mathrm{C}$, cabendo destacar que tais compostos, formados tanto durante a fermentação quanto durante o processo de envelhecimento da bebida, são responsáveis pelo aroma típico e agradável das cachaças envelhecidas. Entretanto, quando presentes em grandes quantidades, podem conferir aroma e sabor enjoativos (BRASIL, 2005b; LIMA et al., 2006).

\subsection{Análise sensorial}

$\mathrm{Na}$ Tabela 2, estão apresentados os dados de aceitação dos consumidores em relação a cor, aroma, sabor e impressão global nas aguardentes de liquor de laranja.

Com base no questionário aplicado no ato do recrutamento dos consumidores para a realização do teste de aceitação, foram selecionados os consumidores que afirmaram gostar de "ligeiramente a muitíssimo" de aguardente envelhecida ou de outras bebidas destiladas envelhecidas, e que têm o hábito de consumir, pelo menos, uma dose $(30 \mathrm{~mL})$ a cada quatro semanas.

Os 60 provadores recrutados apresentaram-se na faixa etária entre 18 e 62 anos, sendo $57 \%$ do sexo masculino e representados principalmente por estudantes de graduação e pós-graduação (82\%).

Entre as três aguardentes de liquor de laranja analisadas ( $A, B$ e C), não foram observadas diferenças significativas em relação aos atributos cor e aroma, porém, em relação aos atributos sabor e impressão global, a amostra B (bateladas de fermentação 4, 5 e 6) diferiu significativamente de forma negativa das demais aguardentes avaliadas. Tais resultados podem estar relacionados com a adaptação do fermento ao longo do processo, produzindo diferentes compostos, os quais podem ter afetado de forma negativa a qualidade sensorial da bebida. Tal fato coincide com a mesma tendência observada na aguardente $C$, que também revelou o comprometimento da qualidade da levedura devido à sua reutilização.

Com base nos resultados obtidos, a prática da reutilização do mesmo pé-de-cuba por mais de três bateladas de fermentação não se mostra aconselhável. Analisando-se a amostra C (bateladas de fermentação 7, 8 e 9), observou-se que, mesmo essa amostra apresentando melhores notas para os atributos sabor e impressão global, quando comparada à amostra $\mathrm{B}$, a demora observada no processo fermentativo e a queda do rendimento, assim como o comprometimento da qualidade química da bebida, indicam ser inviável a reutilização de leveduras de descarte até esse ponto.

Em estudos anteriores relacionados à aguardente de liquor de laranja produzida com o fermento de descarte da indústria cervejeira, Saito (2007) observou nota 5,1 para o atributo impressão global, sem a prática da reutilização do fermento. Já Lorenzeti (2009) obteve nota superior para o mesmo atributo $(7,0)$, o que pode ser explicado pelo processo de envelhecimento ter sido realizado em ancorotes de carvalho, madeira mais conhecida pelos consumidores brasileiros (SAITO, 2007; LORENZETI, 2009).

Durante a realização dos testes de aceitação, também foi solicitado aos consumidores que descrevessem as características de que eles mais gostaram e menos gostaram nas amostras de aguardente de liquor de laranja. Esses consumidores descreveram como "mais gostei" os atributos cor e aroma, nas três amostras avaliadas. A amostra A apresentou $42 \%$ de citações para o atributo cor e $36 \%$ para o atributo aroma. Nas amostras B e C, o atributo aroma foi o que apresentou mais citações (47,3\% e 44,2\%, respectivamente) e, em relação ao atributo sabor, a amostra 1 foi a que obteve o maior percentual (44\%) de "mais gostei", sendo também citados pelos provadores os termos refrescante, suave e frutal, destacando-se, portanto, mais uma vez, a qualidade sensorial da amostra proveniente das três primeiras bateladas de fermentação.

Já entre os atributos descritos como "menos gostei", o sabor foi o mais citado nas três aguardentes ( $A=56 \%$;

Tabela 2. Médias ${ }^{1}$ e desvios padrão da aceitação dos consumidores de aguardentes correspondentes à fração "coração" das aguardentes de liquor de laranja.

\begin{tabular}{ccccc} 
Amostra & Cor & Aroma & Sabor & Impressão global \\
A & $6,83 \pm 1,34^{\mathrm{a}}$ & $6,19 \pm 1,68^{\mathrm{a}}$ & $5,18 \pm 1,90^{\mathrm{a}}$ & $5,35 \pm 1,64^{\mathrm{a}}$ \\
B & $6,84 \pm 2,07^{\mathrm{a}}$ & $6,02 \pm 2,07^{\mathrm{a}}$ & $3,75 \pm 1,62^{\mathrm{b}}$ & $4,33 \pm 1,57^{\mathrm{b}}$ \\
C & $6,96 \pm 1,32^{\mathrm{a}}$ & $5,92 \pm 1,95^{\mathrm{a}}$ & $4,86 \pm 2,10^{\mathrm{a}}$ & $5,13 \pm 1,81^{\mathrm{a}}$ \\
\hline
\end{tabular}

${ }^{1}$ Médias com letras em comum na mesma coluna não diferem significativamente entre si (Teste de Tukey, $p \leq 0,05$ ); $n=60$ consumidores. 
Avaliação do uso da levedura de descarte da indústria cervejeira na obtenção da aguardente de liquor de laranja Paula, C. A. P.; Faria, J. B.

Tabela 3. Teste de qui-quadrado para a intenção de compra dos consumidores em relação às três aguardentes de liquor de laranja (A, B e C).

\begin{tabular}{cccc} 
Intenção de compra & A & B & C \\
\hline Positiva & $15^{\mathrm{a}}$ & $4^{\mathrm{b}}$ & $13^{\mathrm{a}}$ \\
Negativa & $22^{\mathrm{a}}$ & $41^{\mathrm{b}}$ & $27^{\mathrm{b}}$ \\
\hline
\end{tabular}

Letras diferentes na mesma linha indicam diferença significativa entre as bebidas $(p \leq 0,05)$ para o teste de qui-quadrado. Resposta positiva: certamente ou provavelmente compraria; resposta negativa: certamente ou provavelmente não compraria.

$\mathrm{B}=78,9 \%$ e C $=63,5 \%$ ), além dos termos amargo, ácido e pouco doce, também citados.

$\mathrm{Na}$ Tabela 3, está apresentada a intenção de compra dos consumidores para as aguardentes de liquor de laranja produzidas. As aguardentes de liquor de laranja $B$ e $C$ foram as que obtiveram as maiores intenções de compra negativa $(p \leq 0,05)$.

\section{Conclusões}

Com base nos resultados obtidos na análise química e sensorial das aguardentes de liquor de laranja, pode-se afirmar que o uso da levedura de descarte da indústria cervejeira representa uma boa opção no processo de obtenção da referida bebida, sendo possível a realização de até três bateladas de fermentação, sem necessidade de reposição do pé-de-cuba, com garantia da qualidade química e sensorial da bebida.

\section{Agradecimentos}

Os autores agradecem ao Conselho Nacional de Desenvolvimento Científico e Tecnológico (CNPq) pela concessão da bolsa.

\section{Referências}

ALCARDE, A. R.; SOUZA, L. M.; BORTOLETTO, A. M. Ethyl carbamate kinetics in double distillation of sugar cane spirit. Journal of the Institute of Brewing, v. 118, n. 1, p. 27-31, 2012. http://dx.doi.org/10.1002/jib. 14

ASQUIERI, E. R.; SILVA, A. G. M.; CÂNDIDO, M. A. Aguardente de jabuticaba obtida da casca e borra da fabricação de fermentado de jabuticaba. Ciência e Tecnologia de Alimentos, v. 29, n. 4, p. 896-904, 2009. http://dx.doi.org/10.1590/S010120612009000400030

ASSOCIAÇÃO NACIONAL DOS EXPORTADORES DE SUCOS CÍTRICOS - CITRUSBR. O retrato da citricultura brasileira. São Paulo: CITRUSBR, 2016. Disponível em: <http://www.citrusbr. com/>. Acesso em: 30 set. 2016.

ASSOCIATION OF OFFICIAL ANALYTICAL CHEMISTS - AOAC. AOAC Official Method 932.14. Gaithersburg: AOAC International, 1995. v. 2, p. 3.
BARBOSA, A. S.; FLORENTINO, E. R.; FLORÊNCIO, I. M.; ARAÚJO, A. S. Utilização do soro como substrato para produção de aguardente: estudo cinético da produção de etanol. Revista Verde, v. 5, n. 1, p. 7-25, 2010.

BOLUDA-AGUILAR, M.; LÓPEZ-GÓMEZ, A. Production of bioethanol by fermentation of lemon (Citrus limon L.) peel wastes pretreated with steam explosion. Industrial Crops and Products, v. 41, p. 188-197, 2013. http://dx.doi.org/10.1016/j.indcrop.2012.04.031.

BONNEU, M.; CROUZET, M.; URDACI, M.; AIGLE, M. Direct selection of yeast mutants with reduced viability on plates by eritrosine B staining. Analytical Biochemistry, v. 193, n. 2, p. 225-230, 1991. PMid:1714683. http://dx.doi.org/10.1016/00032697(91)90013-J.

BORTOLETTO, A. M.; ALCARDE, A. R. Congeners in sugar cane spirits aged in casks of different woods. Food Chemistry, V. 139, p. 695-701, 2013.

BRADDOCK, R. J. Handbook of citrus by products and processing technology. Gaithersburg: Aspen Publ., 1999. 449 p.

BRASIL. Ministério da Agricultura Pecuária e Abastecimento. Instrução Normativa $n^{\circ} 24$, de 8 de setembro de 2005. Manual operacional de bebidas e vinagres. Diário Oficial [da] República Federativa do Brasil, Brasília, DF, 08 set. 2005a.

BRASIL. Ministério da Agricultura, Pecuária e Abastecimento. Instrução Normativa n ${ }^{\circ}$ 13, de 29 de junho de 2005. Regulamento técnico para fixação dos padrões de identidade e qualidade para aguardente de cana e para cachaça. Diário Oficial [da] República Federativa do Brasil, Brasília, DF, 30 jun. 2005b.

BRINGHENTI, L.; CABELLO, C. Qualidade do álcool produzido a partir de resíduos amiláceos da agroindustrialiização da mandioca. Energia na Agricultura, v. 20, n. 4, p. 36-52, 2005.

GUAGLIANONI, D. G. Análise sensorial: um estudo sobre procedimentos estatísticos e número mínimo de julgadores. 2009. 121 f. Tese (Doutorado em Ciências de Alimentos)-Faculdade de Ciências Farmacêuticas, Universidade Estadual "Júlio de Mesquita Filho", Araraquara, 2009.

INSTITUTO ADOLFO LUTZ - IAL. Normas analíticas: métodos químicos e físicos para análise de alimentos. 4. ed. São Paulo: Secretaria da Saúde, 2005. v. 1, p. 104, 407-419.

LANZA, C. M. Processed and derived products of orange. Citrus Fruits, p. 1346-1354, 2003.

LIMA, A. J. B.; CARDOSO, M. G.; GUERREIRO, M. C.; PIMENTEL, F. A. Emprego do carvão ativado para remoção de cobre em cachaça. Química Nova, v. 29, n. 2, p. 247-250, 2006. http:// dx.doi.org/10.1590/S0100-40422006000200014.

LORENZETI, N. C. Perfil sensorial e aceitabilidade de aguardentes de "liquor" de laranja. 2009. 140 f. Dissertação (Mestrado em Ciência de Alimentos)-Faculdade de Ciências Farmacêuticas, Universidade Estadual "Júlio de Mesquita Filho", Araraquara, 2009. 
Avaliação do uso da levedura de descarte da indústria cervejeira na obtenção da aguardente de liquor de laranja

Paula, C. A. P.; Faria, J. B.

MEILGAARD, M. C.; CARR, B. T.; CIVILLE, G. V. Sensory evaluation techniques. Boca Raton: CRC Press, 2006.

MIRANDA, B. M.; HORII, J.; ALCARDE, A. R. Estudo do efeito da irradiação gamma $\left({ }^{60} \mathrm{CO}\right)$ na qualidade da cachaça e no tonel de envelhecimento. Ciência e Tecnologia de Alimentos, v. 26 , n. 4, p. 772-778, 2006. http://dx.doi.org/10.1590/S010120612006000400010.

MUTTON, M. J. R.; MUTTON, M. A. Aguardente de cana. In: VENTURINI FILHO, W. G. (Org.). Bebidas alcoólicas: ciência e tecnologia. São Paulo: Blucher, 2010. v. 1. 492 p.

PIGGOTT, J. R. Ç.; SHARP, R. Ç.; DUNCAN, R. E. B. The science and technology of whiskies. New York: Longman Scientific \& Technical, 1989. 410 p.

ROÇAFA JUNIOR, H.; PADOVAN, F. C.; FARIA, J. B. Obtenção de uma bebida fermento-destilada a partir do "licor" de laranja. Alimentos e Nutrição, v. 16, n. 4, p. 321-325, 2005.

SAITO, F. H. S. F. Utilização de fermento de descarte de cervejaria na produção de aguardente de "licor" de laranja. 2007. 75 f. Dissertação (Mestrado em Ciência de Alimentos)Faculdade de Ciências Farmacêuticas, Universidade Estadual "Júlio de Mesquita Filho", Araraquara, 2007.
SOUZA, G. R.; CARDOSO, M. G.; ANJOS, J. P.; VILELA, F. J.; SACZK, A. A. Avaliação da qualidade de cachaças vendidas em estabelecimentos comerciais da cidade de Varginha-MG. Revista da Sociedade dos Técnicos Açucareiros e Alcooleiros do Brasil, v. 27, p. 50-53, 2009.

Villanueva, N. D. M.; PetenAte, A. J.; Silva, M. A. A. P. Performance of the hybrid hedonic scale as compared to the traditional hedonic, self-adjusting and ranking scales. Food Quality and Preference, v. 16, n. 8, p. 691-703, 2005. http:// dx.doi.org/10.1016/j.foodqual.2005.03.013.

WILKINS, M. R.; WIDMER, W. W.; GROHMANN, K. Simultaneous saccharification and fermentation of citrus peel waste by Saccharomyces cerevisiae to produce ethanol. Process Biochemistry, v. 42, n. 12, p. 1614-1619, 2007. http://dx.doi. org/10.1016/j.procbio.2007.09.006.

ZINNAI, A.; VENTURI, F.; SANMARTIN, C.; QUARTACCI, M. F.; ANDRICH, G. Kinetics of D-glucose and D-fructose conversion during the alcoholic fermentation promoted by Saccharomyces cerevisiae. Journal of Bioscience and Bioengineering, v. 115, n. 1, p. 43-49, 2013. PMid:22986306. http://dx.doi.org/10.1016/j. jbiosc.2012.08.008. 